\title{
EDUCATIONAL EQUITY AND THE APPLICATION OF TECHNOLOGY: A CRITICAL APPROACH
}

\author{
Terri Brian
}

\section{INTRODUCTION}

The provision of equitable learning opportunities and outcomes to increasingly diverse learner populations is an ongoing global challenge (UNESCO, 20 I4). In Aotearoa New Zealand, this challenge is particularly significant where a large achievement gap is apparent, and frequently related to ethnicity or socio-economic background. Despite numerous policy interventions by successive governments, data shows that those from minority populations are still over-represented by inequalities in educational opportunity and achievement. As a result, the need for education that overcomes socio-economic and socio-cultural barriers and differences continues to present a critical challenge for policymakers and educators. For many, the additional delivery options provided by technology, are seen as a means of providing more equitable opportunities and outcomes within tertiary education. The implementation and application of this technology, however, is in many cases not supported by robust pedagogical knowledge, or by a thorough understanding of the social and cultural contexts in which it operates. Despite widespread and enthusiastic rhetoric about its use in educational and social reform, the integration of educational technology has, to date, had a relatively superficial impact on equity or learning and teaching practices and, instead, has often tended to be applied to the reworking of the status quo.

This article suggests that, although educational technology is a powerful tool in the promotion of equity, its application must be accompanied by an understanding of how it supports, enhances or alters learning opportunities and power relationships. If we apply a critical theory perspective to the use of technology in tertiary education, we are able to see it as a catalyst for empowerment, rather than as a pre-determined policy imperative. This transforms it into a tool that can support equity and social change, and lays the foundations for pedagogies that support the empowerment of marginalised and excluded learner populations.

\section{THE CURRENT CONTEXT}

According to Bolton (2017), an equitable education system is one where all learners, regardless of ethnicity, culture, socio-economic status or ability, can succeed. This may mean that previously excluded populations are provided with educational opportunities to enhance their lives and employment prospects. Alternatively, it may involve redressing imbalances in the types of learners attracted to educational institutions. Educational equity is defined by the OECD in terms of fairness and inclusion. Fairness ensures that personal and social circumstances do not prevent learners from achieving their academic potential. Inclusion requires the setting of basic minimum educational standards and outcomes, to be achieved by all learners regardless of background, personal characteristics, circumstances or location (OECD, 2008). UNESCO (2015) identifies educational equity as an important global priority in the promotion of a vision of holistic, lifelong learning. Within this vision, equity is achieved, firstly, through the advancement of inclusion and the reduction and elimination of disparities in educational outcomes; and, secondly, by sustaining a focus on equipping people with the skills, knowledge and values necessary to obtain satisfactory employment and participate as national and global citizens. The need for 
safe and enabling learning environments, consisting of sufficient numbers of qualified and motivated educators, and supported by management, technologies and infrastructure, is also recognised. Importantly, promoting and achieving educational equity is not about treating all learners exactly the same, but about providing interventions that promote equality of opportunity (Salmi \& Bassett, 20I4).

In Aotearoa New Zealand, the objectives of the National Education and Learning Priorities (NELP) and the Tertiary Education Strategy (TES) reflect these definitions, and seek to prioritise learners who, historically, have not been well served by the current system (Ministry of Education, 2020). Participation in education is also seen as key to redressing regional imbalances where fragile local economies, higher rates of unemployment, greater numbers of at-risk children and young people, and housing affordability are significant issues (Centre for Social Impact, 20 I8). Educational institutions are encouraged to focus on ensuring that places of learning are inclusive and barrier-free, taking account of diversity in language, culture and identity, and developing staff to provide high-quality learning experiences that support equitable outcomes and opportunities (Ministry of Education, 2020).

Over the past few decades, however, and despite the various projects and policies of governments and other institutions, only fairly limited advancements in educational equity have resulted. Although the OECD's latest economic survey of Aotearoa New Zealand shows an increase in the proportion of tertiary-educated adults, and attainment similar to the OECD average, there are ongoing concerns about disparities in educational outcomes. These disparities are substantial, and especially evident at degree level and higher. They also include strong intergenerational persistence and ethnic inequalities (OECD, 2020). For example, although tertiary attainment rates have been rising for Māori and Pasifika learner groups, they are not improving at the same pace as those of other ethnicities (Ministry of Education, 2021).

The stories behind many of these outcome and achievement gaps, are often related to the challenges associated with accessing education. Salmi and Bassett (2014) suggest that equity and access are terms commonly used interchangeably, but that equity is not created by just entering tertiary education. It involves having equal opportunities to select from a range of existing institutions and academic pathways, and being equipped to persist, progress, and complete programmes of study. Within most tertiary institutions in Aotearoa New Zealand, learner populations include both school leavers and those who may have been away from formal education for some time. Many already have extensive whānau and employment responsibilities, while some live in isolated, rural or semi-rural communities (Alexander-Crawford et al., 2015). Research has shown that the need to maintain employment, leave home, change location or incur travel costs are all significant deterrents or barriers to accessing tertiary education, and can negatively impact learner retention and success (Stone, 2017). Additionally, inadequate academic preparation and support, competing whānau interests, cultural capital, and personal uncertainties are potential obstacles to successful participation (Eggins 2010).

In response to many of these challenges, the use of digital technology is seen as key to expanding educational opportunities, and enabling tertiary learners to balance study with other demands and commitments. Inarguably, the increased options provided by online and flexible programme delivery can offer those in remote locations, or with other existing responsibilities, the chance to update their knowledge and skills while saving costs and allowing a more workable schedule (Park and Choi, 2009). This line of thinking has led many policymakers and institutions to attempt to use technology to close persistent gaps in access, in the belief that it will mitigate disadvantage and increase educational equity (Eynon \& Geniets, 2016). Additionally, in our current context, we are encountering the massive disruption brought about by the global pandemic and, visions of digitally-enhanced and socially-distanced education have hastened the transition to online learning solutions. Silva et al. (202I) however, point to the ways in which this unexpected use has demonstrated the need to guarantee conscious and democratic access to technology-based education. It appears that the focus on the use of educational technology, not only raises new opportunities, but also runs the risk of emphasising exclusion for often already marginalised, learner groups. 


\section{DIGITAL LITERACY}

In addition to difficulties associated with participating in tertiary education, marginalised and vulnerable members of society are more likely to experience barriers related to the access and use of technology (Gonzales et al., 20I8). In Aotearoa New Zealand, lack of internet connectivity and appropriate hardware predominantly affects those in rural or low socio-economic communities, such as Māori and Pasifika, people with disabilities, the elderly, refugees and migrants with English as a second language, and people with limited educational experience (Hartnett \& Fields, 2019). Eynon and Geniets (2016) suggest that, although the term "digital divide" has historically been used to describe these observed inequalities, it suggests a simple dichotomy of those who have access to technology and those who do not. It also assumes that those who have access are able to use it effectively. Schwenger (2016), suggests that this framing does not acknowledge the implicit digital literacy demands within many online learning activities and courses, and therefore, some learners may experience these as a barrier to success.

Studies of technological change and social inequity have identified correlations between differential access, usage, attitudes and skills, which in turn affect factors such as life chances, civic engagement, social capital and education (Robinson et al., 2015). According to Hartnett and Fields (2019), when individuals and communities are given equal access to technology, it is digital literacy that sets apart those who have the resources to take advantage of its benefits. There are numerous definitions of digital literacy, however Buckingham (2007), describes it as more than the ability to access digital tools, or use them for learning, and suggests that it also involves developing a broad, critical understanding, that addresses their social, economic and cultural implications.

In tertiary education, an imbalance is often reflected between learners' often well-developed digital technology skills and their approaches to the use of information. Young, seemingly technologically proficient learners are often perceived to be "digital natives", raised in a world surrounded by digital technology and, assumed to be comfortable and familiar with how to use it (Prensky, 200I). In response to this accepted technical capability, we often expect learners to be able to apply often fairly complex digital literacy skills, or to be capable of improving them independently (Drew \& Forbes, 2017). Ultimately, Buckingham (2007) believes, the elements of digital literacy should be seen as essential in the context of democratic participation, equity and social inclusion and adequately scaffolded and extended throughout curriculum content and design.

\section{PEDAGOGY}

Over the past few decades, educational theory has undergone a paradigm shift whereby the application of new and emerging pedagogies has provided possibilities for social and learner-centred learning opportunities. Within these paradigms, learning environments are defined by authentic, discussion-based, inquiry-focused and collaborative activities that support experiential learning and critical reflection (Girvan \& Savage, 2010). Although digital tools and technologies have immense potential to support these epistemologies, they require educators to possess the necessary expertise and pedagogical knowledge to use them effectively (Papendieck, 2018).

Trewern and Wenmoth (2008) suggest that understanding of the use of educational technology as an equity tool is not widespread. Despite its rapid development and permeation, pedagogical practices, especially in tertiary education, have largely remained unchanged. According to Sims (2017), far from being used as tools to promote equity, many technological innovations have merely supported existing learning and teaching practices, used for flexibility or convenience rather than for the development of strategies that facilitate deeper learning. Clemmons et al. (20/4) believe this is the result of initiatives and professional development programmes that are often focused on the technology itself, rather than on the pedagogies that support its application.

Pedagogical approaches identified as useful for promoting educational equity are largely based on social-constructivist models that aim to integrate learners' cultural attributes with the collaborative construction of knowledge. They also maintain a focus on the distribution of power; access to materials and resources; and equal rights and opportunities 
in all learning environments. Interaction forms an essential part of a social-constructivist epistemology, defined in an online environment by activities that support experiential learning and critical reflection (Eisner, 2005). This approach may represent a fundamental change in the roles and identities of learners and teachers, and can be difficult to change, as these models are often deeply embedded in institutional culture. The effectiveness of these approaches are also influenced by the design of the systems and programmes that support them (Girvan \& Savage, 20 I0).

Philip and Olivares-Pasillas (2016) suggest that without adequate consideration of pedagogy or the systemic inequities that exist within tertiary education, the introduction of new technologies leads to the same cycle of unfulfilled promises of digitally-inspired reform. The meaningful use of educational technology therefore, requires and implies transformations in our own roles, as well as in those of learners and the wider community, and in the criteria that determine and validate the processes of learning, teaching and the production of knowledge (Strydom et al., 2021).

\section{A CRITICAL THEORY PERSPECTIVE}

Historically, issues relating to widening educational access and ensuring the success and retention of under-represented groups are deeply rooted in history and culture and contained within complex social, economic and political structures (Altbach et al., 2009). As a framework for examining these issues, critical theory exposes and challenges some of the biases that may undermine and alienate learners. Crucially, it focuses on creating transformative action that leads to social change, and emphasises the provision of knowledge and understanding necessary to free people from oppression (Brookfield, 2005).

In the later part of the twentieth century, critical theorists (e.g. Freire, 1972; Giroux, 1980; McLaren, 1994), assisted in the development of frameworks and pedagogies relating to education, social transformation and personal freedom. These theorists argued that the primary purpose of education is to enable learners to develop awareness and agency, in order to liberate themselves from oppression. Freire (1972) in particular, challenged traditional methods and systems of education, and observed the ways in which these tend to reflect and favour those that understand them. Within these systems, challenges faced by marginalised populations are generally viewed as inherent and, because underlying issues are not recognised, existing inequities are replicated. As a result, learners from dominant cultures and groups continue to succeed, while those who are marginalised continue to struggle (Rossatto, 2005). In general terms, applying a critical theory paradigm to educational equity, involves identifying, challenging and changing the way in which dominant ideologies result in the acceptance of marginalisation and oppression.

According to Wang and Torrisi-Steele (2015), although a critical theory perspective is often found within disciplines such as pedagogy and curriculum studies, it is less commonly applied to the use of educational technology. Selwyn (2015) suggests that, viewed through a critical lens, the use of technology in education, can be seen as, not only an effective tool for enabling equity through social change, but also as the result of power relations and multiple contradictory interests. Within tertiary education, a pervasive determinism commonly misaligns the use of technology with the quality and effectiveness of learning and teaching, and it is therefore attributed with an intrinsic quality, that diverts attention from how it is being applied. These applications are, additionally, often driven by the needs of the more dominant and powerful groups in society. In this way, far from being neutral, educational technology helps to convey values and biases that reflect its development and carries with it, certain conceptions about learning and teaching resulting from the various interests of those involved in its design (Wang \& Torrisi-Steele, 2015).

In order to create opportunities for equitable achievement in tertiary learning environments, there remains a need for the transformation of technology-based delivery techniques towards those that empower learners and increase their chances for success. By applying a critical lens, we can see the use of educational technology as a tool to support learners in the development of the knowledge and skills they need to achieve equity. This epistemology, requires that we understand how dominant educational, social and political systems shape learning 
and understanding. We must also be willing to identify and challenge our own assumptions about how we use educational technology, and its role in enabling equitable outcomes and achievement. In this way, we can develop and apply the appropriate pedagogical knowledge and tools to address these issues within our practice (Brinkmann \& Tanggaard, 2010).

\section{CONCLUSION}

It is clear that, as educators, we need to be taking an active role in empowering learners, and enabling them to create social change. A better understanding of the systemic and pervasive causes of inequity in wider society is needed, however, before we can begin to address those that have manifested themselves within tertiary education. Equality of opportunity, and making learning available for all, without discrimination, is a concern, not least because of the way in which education and knowledge impact on people's life opportunities. A commitment to educational equity requires ensuring that all learners have the requisite knowledge, skills and competencies to be successful; that individual circumstances do not create obstacles to achieving potential; and that all learners are able to achieve a minimum level of skill acquisition. Achieving this, involves closing gaps in access and participation, and ensuring that all learners, irrespective of their economic or socio-cultural backgrounds, are provided with well-designed learning tools and experiences.

While the inherent potential of educational technology as an equity tool is powerful, its benefits should not be presumed and, its effective use necessitates a pedagogical understanding beyond the boundaries of the digital divide. This involves expanding our educational repertoires and designing learning opportunities that, not only improve access and participation, but also help learners to make sense of multiple sources and representations of knowledge. A critical approach to teaching practices, and to the use of technology in the learning environment, can support us to question and develop our knowledge of equity-related pedagogies. This, in turn, helps us address the underlying causes of existing inequities, and their accompanying social, cultural and technological complexities.

Terri Brian lives in Whangärei in Tai Tokerau Northland and recently completed her Master of Contemporary Education, where she focused her final project on educational equity. Terri is interested in exploring how technology and the application of contemporary pedagogies and practices can help to improve educational opportunities and outcomes.

(10) https://orcid.org/0000-0002-4923-4874

\section{REFERENCES}

Alexander-Crawford, P., Ewen, M., Fraser, C., \& Dennis, R. (20I5). Kai tu tangata ai tātou, puta noa i te ao: Enabling students to become life-ready, study-ready and work-ready in TeTai Tokerau - Northland. https://ako.ac.nz/assets/Knowmcgeeledge-centre/ RHPF-N69-Enabling-students-in-Northland/REPORT-Kai-Tu-Tangata-ai-Tatou-Puta-Noa-i-Te-Ao.pdf

Altbach, P. G., Reisberg, L., \& Rumbley, L. E. (2009). Trends in global higher education: Tracking an academic revolution. UNESCO 2009 World Conference on Higher Education. http://www.cep.edu.rs/public/Altbach,_Reisberg,_Rumbley_Tracking_an_ Academic_Revolution,_UNESCO_2009.pdf

Bolton, S.W. (2017). Educational equity in New Zealand: Successes, challenges and opportunities. https://www.fulbright. org.nz/wp-content/uploads/2017/08/BOLTON-Educational-Equity-in-New-Zealand-Successes-Challenges-andOpportunities-.pdf

Brinkmann, S., \& Tanggaard, L. (2010). Toward an epistemology of the hand. Studies in the Philosophy of Education 29, $243-257$. https://doi.org/l0.1007/s/1217-009-9164-0

Brookfield, S.D. (2005). The power of critical theory: Liberating adult learning and teaching. Jossey-Bass 
Buckingham, D. (2007). Digital media literacies: Rethinking media education in the age of the Internet. Research in Comparative and International Education, 2, 42-55.

Centre for Social Impact. (2018). Understanding the landscape of Auckland \& Northland: An evidence review. https://do6qmrbufqcd2. cloudfront.net/I00I/I8-fn-0070-evidence-review-04.pdf

Clemmons, K., Nolen, A., \& Hayn, J. A. (2014). Constructing community in higher education regardless of proximity. In S. Mukerji \& P. Tripathi (Eds), Handbook of research on transnational higher education (pp. 713-729). Information Science Reference

Drew, L., \& Forbes, D. (2017). Devices, distractions and digital literacy: Bring your own device to Polytech. Teachers and Curriculum, 17(2), 61-70. http://dx.doi.org//0.15663/tandc.v17i2.157

Eggins, H. (20l0). Access and equity: Comparative perspectives. Global Perspectives on Higher Education, (20). Sense Publishers.

Eisner, E. (2005). The whole child. Educational Leadership, 63(I), 14-18 http://www.ascd.org/publications/educational-leadership/ sept05/vol63/num0I/Back-to-Whole.aspx

Eynon, R., \& Geniets, A. (2016). The digital skills paradox: How do digitally excluded youth develop skills to use the internet? Learning, Media and Technology, 4 I (3), 463-479. https://doi:10.1080/17439884.2014.1002845

Freire, P. (1972). Pedagogy of the oppressed. Penguin.

Giroux, H. A. (1980). Critical theory and rationality in citizenship education. Curriculum Inquiry, 10(4), 329-366. https://doi. org/10.2307/1179823

Girvan, C., \& Savage, T. (2010). Identifying an appropriate pedagogy for virtual worlds: A Communal Constructivism case study. Computers \& Education, 55, 342-349. https://doi.org/l0.1016/j.compedu.2010.01.020

Gonzales, A. L., McCrory Calarco, J., \& Lynch, T. K. (2018). Technology problems and student achievement gaps: A validation and extension of the technology maintenance construct. Communication Research, 47(5), 750-770. https://doi. org/10.1177/0093650218796366

Hartnett, M., \& Fields, A. (2019). Digital inclusion in New Zealand. Journal of Open, Flexible and Distance Learning, $23(2), 1-4$. https://search.informit.org/doi/l0.3316/informit.980696247612507

McLaren, P. (1994). Life in schools: An introduction to critical pedagogy in the foundations of education. Longman.

Ministry of Education (2020). The statement of national education and learning priorities (NELP) \& tertiary education strategy (TES). https://www.education.govt.nz/our-work/overall-strategies-and-policies/the-statement-of-national-education-andlearning-priorities-nelp-and-the-tertiary-education-strategy-tes/

Ministry of Education (2021). Educational attainment in the adult population. https://www.educationcounts.govt.nz/__data/assets/ pdf_file/0007/987I/Educational-attainment-in-the-adult-population-Indicator.pdf

OECD. (2008). Ten steps to equity in education. [Policy brief]. https://www.oecd.org/education/school/39989494.pdf

OECD (2020). Education at a glance 2020: OECD indicators. https://www.oecd-ilibrary.org/education/education-at-a-glance2020_69096873-en

Papendieck, A. (2018). Technology for equity and social justice in education: A critical issue overview. Texas Education Review, 6(I), I-9. https://doi:10.1578I/T2891278V

Park, J. H., \& Choi, H. J. (2009). Factors influencing adult learners' decision to drop out or persist in online learning. Journal of Educational Technology \& Society, 12(4), 207-217. https://www.learntechlib.org/p/74987/

Philip, T. M., \& Olivares-Pasillas, M. C. (2016). Learning technologies and educational equity: Charting alternatives to the troubling pattern of big promises with dismal results. http://tmp.bol.ucla.edu/Philip_TCRCommentary.pdf

Prensky, M. (200I). Digital natives, digital immigrants. On the Horizon, 9(5), I-6. https://www.marcprensky.com/writing/ Prensky\%20-\%20Digital\%20Natives,\%20Digital\%20Immigrants\%20-\%20Partl.pdf

Robinson, L., Cotten, S. R., Ono, H., ... Stern, M. J. (2015). Digital inequalities and why they matter. Information, Communication \& Society, 18(5): 569-582. https://doi.org/I0.1080/I369/18X.2015.1012532

Rossatto, C. A. (2005). Engaging Paulo Freire's pedagogy of possibility. Rowman and Littlefield.

Salmi, J., \& Bassett, R. M. (2014). The equity imperative in tertiary education: Promoting fairness and efficiency. International Review of Education, 60(3), 36I-377. doi:http://dx.doi.org.op.idm.oclc.org//0.1007/s I II59-013-939|-z

Schwenger, B. (2016). Enhancing students' tertiary blended learning experience through embedding digital information literacy. Journal of Perspectives in Applied Academic Practice, 4(I). https://unitec.researchbank.ac.nz/handle/I0652/358I

Selwyn, N. (2015). Technology and education: Why it's crucial to be critical. In S. Bulfin, N. Johnson, \& C. Bigum (Eds.), Critical perspectives on technology and education (pp. 245-255). Palgrave Macmillan. https://link.springer.com/chapt er/l0.1057/978|13738545I_I4 
Silva, M. M. M., Alves, D. R., \& Ferreira, M. J. (202I). Notes about digital education in democracy and education about the European Union. In: L. Gómez Chova, A. López Martinez, I. Candel Torres, INTED202I Proceedings: I5th International Technology, Education and Development Conference, pp. 2408-2412. http://hdl.handle.net/I1328/3422

Sims, C. (2017). Disruptive fixation: School reform and the pitfalls of techno-idealism. Princeton University Press.

Strydom, S. C., Wessels, H., \& Anley, C., 2021. Moving beyond the tools: Pre-service teachers' views on what they value in a digital literacy short course. South African Journal of Childhood Education, I/ (I), a929. https://doi.org/I0.4l02/ sajce.v I lil.929

Trewern, A., \& Wenmoth, D. (2008). Evaluation of student facing web-based services: Report to the Ministry of Education: WickED (CORE education). https://www.educationcounts.govt.nz/_data/assets/pdf_file/0005/27824/890_WickED-CORE.pdf

UNESCO. (2014). Teaching and learning: Achieving quality for all; EFA global monitoring report, 2013-2014. https://unesdoc.unesco. org/ark:/48223/pf0000225660

UNESCO. (2015). Thematic consultation on education in the post-2015 development agenda, 18-19 March 2013 - Dakar, Senegal: Summary of Outcomes. http://www.unesco.org/new/fileadmin/MULTIMEDIA/HQ/ED/pdf/post-20I5-summaryoutcomes.pdf

Wang, V.C.X. and Torrisi-Steele, G. (2015), Online Teaching, Change, and Critical Theory. New Horizons in Adult Education and Human Resource Development, (27), 18-26. https://doi.org/I0.1002/nha3.20108 